\title{
Surface-Enhanced Raman Scattering of Bacteria in Microwells Constructed from Silver Nanoparticles
}

\author{
Mustafa Çulha, ${ }^{1}$ M. Müge Yazıcı, ${ }^{1}$ Mehmet Kahraman, ${ }^{1}$ \\ Fikrettin Şahin, ${ }^{1}$ and Sesin Kocagö $z^{2}$ \\ ${ }^{1}$ Genetics and Bioengineering Department, Faculty of Engineering and Architecture, Yeditepe University, Istanbul 34755, Turkey \\ ${ }^{2}$ Acıbadem University, School of Medicine, Department of Infectious Diseases, Büyükdere Cad. No. 40, Maslak, \\ Istanbul 34457, Turkey
}

Correspondence should be addressed to Mustafa Çulha, mculha@yeditepe.edu.tr

Received 2 February 2012; Revised 19 April 2012; Accepted 1 May 2012

Academic Editor: Nickolay Lavrik

Copyright (c) 2012 Mustafa Çulha et al. This is an open access article distributed under the Creative Commons Attribution License, which permits unrestricted use, distribution, and reproduction in any medium, provided the original work is properly cited.

\begin{abstract}
Whole bacterial cell characterization is critically important for fast bacterial identification. Surface-enhanced Raman scattering (SERS) is proven to be powerful technique to serve such a goal. In this study, the characterization of whole bacterial cells in the microwells constructed from colloidal silver nanoparticles (AgNPs) with "convective-assembly" method is reported. The proper size of the microwells for the model bacteria, Escherichia coli and Staphylococcus cohnii, is determined to be $1.2 \mu \mathrm{m}$ from their electron microscopy images. A minimum dilution factor of 20 is necessary for the bacterial samples collected from growth media to diminish the bacterial aggregation to place the bacterial cells into the microwells. The constructed microwell structures are tested for their bacterial SERS performance and compared to the SERS spectra obtained from the samples prepared with a simple mixing of bacteria and AgNPs for the same bacteria. The results indicate that microwell structures not only improve the spectral quality but also increase the reproducibility of the SERS spectra.
\end{abstract}

\section{Introduction}

The spectroscopic characterization of biological structures such as bacterial and living eukaryotic cells as a whole is an important concept to understand not only the biochemical structure of organization in their natural environment but also cellular processes inside of living cells. The surfaceenhanced Raman scattering (SERS) is an emerging and promising technique to achieve such a goal and its potential has not fully explored to study bacterial and eukaryotic cells as whole yet. The supremacy of SERS mostly comes from its capability to provide molecular information from molecules or molecular structures located very close to nanostructured surfaces of silver or gold with a very limited influence of water, which is a significant component of biological structures.

The several groups explored the utility of SERS for bacterial characterization, discrimination and identification [1-13]. A simple mixing of bacterial cells and colloidal nanoparticles provides a straightforward way of preparing samples. However, due to the nonuniform nature of the prepared sample with the simple mixing, the acquired SERS spectra show variation from sample-to-sample and spot-tospot on the same sample. Although there is strong evidence that the certain locations on the bacterial cell wall preferably strongly interact with AgNPs, the variations due to the sample preparation must be minimized for proper interpretation of the SERS spectra. Therefore, a more systematic approach is necessary to collect interpretable spectra from bacteria.

A patterned surface may provide a more suitable environment for bacterial cells to experience the surface plasmons of noble metal nanoparticles used to construct the patterned surfaces. The "convective-assembly" is a technique used to control assembly of nano- and micrometer size particles into two-dimensional (2D) and three-dimensional (3D) structures. The self-assembly of colloidal particles in thin evaporating films is the basis of the technique $[14,15]$. During the assembly process, the small, nanometer size, gold or silver nanoparticles fill the voids around the large, micrometer size, latex particles forming a colloidal crystal. 
After the assembly process is completed, the latex particles can be washed from the surface with an organic solvent. The remaining porous three-dimensional structure can be used as a SERS substrate [16]. The use of this technique was also reported to prepare coatings from sterically protected and silica-encapsulated nanoparticles and porous 3D gold structures for SERS [16-20].

In this study, we prepared microwells on glass surfaces constructed from AgNPs with "convective-assembly" method. The surfaces structured with microwells were used for as a SERS substrate to characterize whole bacteria cells. The SERS spectra obtained from the bacterial cells located into microwells and simply mixed with the AgNPs for two model bacteria, E. coli and S. cohnii, were compared.

\section{Experimental}

2.1. Chemicals. $\mathrm{AgNO}_{3}(99.5 \%)$ and nutrient broth were purchased from Fluka (Seelze, Germany). Sodium citrate (99\%) was purchased from Merck (Darmstadt, Germany). The latex microspheres were purchased from Invitrogen (Eugene, OR) as surfactant-free white sulfate latex. Microscope slide was purchased from Citoglass (China). HPLC grade dichloromethane stabilized with ethanol was purchased from Labkim (Istanbul, Turkey).

2.2. Preparation of Colloidal AgNPs. The colloidal AgNPs were prepared with a method reported by Lee and Meisel method [21]. In this, a $90 \mathrm{mg}$ of $\mathrm{AgNO}_{3}$ was dissolved in $500 \mathrm{~mL}$ of distilled water and heated until boiling. Then, a $10 \mathrm{~mL}$ of $1 \%$ sodium citrate solution was added into this boiling solution. This mixture was kept boiling until final volume is reached $250 \mathrm{~mL}$. The obtained AgNP colloidal suspension was characterized by using UV spectroscopy and SEM. The maximum absorption wavelength of the AgNP colloidal suspension is typically at around $420 \mathrm{~nm}$ with an average size of $60 \mathrm{~nm}$. The density of the AgNPs in the suspension was estimated as $2.0 \times 10^{11}$ particles $/ \mathrm{mL}$.

2.3. Colloidal Suspension Concentration. An increased colloidal AgNP suspension concentration is required to construct the microwell structures. Therefore, a 100-fold increase in AgNP colloidal suspension concentration from its original concentration was needed. This was achieved by centrifuging a $200 \mathrm{~mL}$ of the AgNP colloidal suspension $5500 \mathrm{rpm}$ for $30 \mathrm{~min}$ and removing the supernatant to leave only $2 \mathrm{~mL}$ of concentrated suspension.

2.4. Preparation of Bacteria Samples. Escherichia coli (35218 ATCC) and Staphylococcus cohnii samples were obtained from our microorganism collection (Yeditepe University, Genetics and Bioengineering Department). Before using the bacteria, their identification was verified by Sherlock Microbial Identification System version 4.5 (MIDI, Newark, Delaware). The bacteria were cultivated for $24 \mathrm{~h}$ at $37^{\circ} \mathrm{C}$ on nutrient broth. The collected bacteria washed three times by adding $20 \mathrm{~mL}$ of deionized water at centrifuging at $5000 \mathrm{rpm}$ for ten $10 \mathrm{~min}$ and by discarding the supernatant. For the

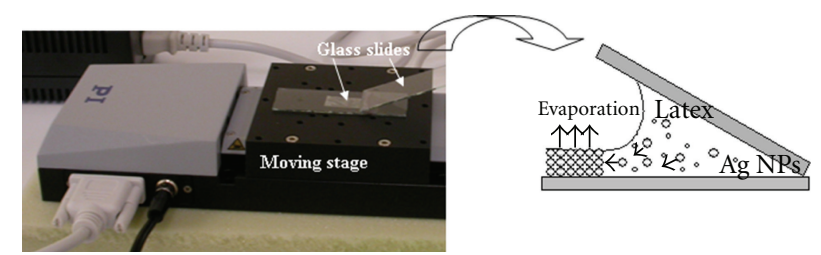

Figure 1: The "convective-assembly" setup used to construct the microwells in this study.

simple mixing method, a $5 \mu \mathrm{L}$ of each washed bacterium was added into $100 \mu \mathrm{L}$ AgNPs suspension. Then, they were mixed with a vortex and $5 \mu \mathrm{L}$ of this homogeneous mixture was spotted onto a $\mathrm{CaF}_{2}$ slide. The spot was allowed to dry at room temperature about $15 \mathrm{~min}$ before the analysis.

2.5. Preparation of Microwells. The AgNPs and latex micro spheres $(1.2 \mu \mathrm{m})$ were mixed and coated onto glass slides using "convective-assembly." First, the glass slides were washed with chromic acid to clean the surface. Then, the washed slides were rinsed with deionized water and dried before coating procedure at ambient temperature. The mixture containing silver and latex nanoparticles was located at the cross-section of two glasses meeting with an angle of $\sim 23$ and the lower glass slide fixed on the moving stage was moved with a certain speed with the help of a controller (PI, Germany). Figure 1 shows the "convective-assembly" setup. The details of the experimental setup were also explained elsewhere [22]. As different from the reported setup, the glass slide attached to the moving stage was mobile other than the glass slide placed with an angle. The concentrated AgNPs and a desired size of latex microparticle suspension can be used to construct the preferred size of microwells. Due to the size of the bacteria used in this study, the $1.2 \mu \mathrm{m}$ latex microspheres were used to construct the microwells. The ratio of latex colloidal suspension to AgNPs was 1:9 in final mixture before spotting at the cross-section of two glass slides. The speed of the stage that the glass slide was placed was in the range of $1.0-2.0 \mu \mathrm{m} / \mathrm{s}$.

2.6. Preparation of Bacterial Samples on Surfaces. The initial bacterial counts were calculated with a dilution method and found as $1.3 \times 10^{7}$ and $7.4 \times 10^{7} \mathrm{CFU} / \mathrm{mL}$ for $S$. cohnii and E. coli, respectively. From this sample, $5 \mu \mathrm{L}$ was taken and completed to $100 \mu \mathrm{L}$ with distilled water. Then, a $2 \mu \mathrm{L}$ aliquot was spotted on the microwell-structured surface. This procedure generated enough bacteria in the microwells and the SERS experiments were performed on these surfaces. The area where bacterial suspension spotted remained in the range of $2.5 \pm 0.4 \mu \mathrm{m} \times 1.5 \pm 0.3 \mu \mathrm{m}$ for both bacterial samples. The number of bacteria in each microwell changes depending on the aggregation characteristics of the bacterial cells. Since the shape of $S$. cohnii cells is spherical with an average diameter of $0.8 \mu \mathrm{m}$, it is possible to locate about 4 cells into one $1 \mu \mathrm{m}$ size well. The shape of $E$. coli cells is rodlike with an average length and diameter of 1.8 and $0.9 \mu \mathrm{m}$, respectively. Thus, only one or two cells can fit into one 
microwell depending on the orientation of the cells. Note that the localization of the bacterial cells in the microwells seemed trivial.

2.7. Raman Instrumentation. All measurements were performed using a Renishaw inVia Reflex Raman spectroscopy system (Renishaw Plc., New Mills, Wotton-under-Edge Gloucestershire, UK) An $830 \mathrm{~nm}$ laser was used for all SERS experiments. The laser power on the sample was $3 \mathrm{~mW}$ with a time $10 \mathrm{sec}$ exposure time. The spot size of the laser is about 1 micron when the 50x $(\mathrm{NA}=0.75)$ objective is used. The wavelength of the instrument was automatically calibrated using an internal silicon wafer, and the spectrum was centered at $520 \mathrm{~cm}^{-1}$.

2.8. Scanning Electron Microscope. The characterization of the prepared surfaces was performed with a Karl Zeiss EVO 40 model SEM instrument. The SEM images of the bacterial cells in the microwells were acquired upon drying at ambient temperature. For simple mixing experiments, the images were acquired after mixing the colloidal suspension and bacterial cells and drying on a scanning electron microscope sample stub at ambient temperature. The accelerating voltage was $10 \mathrm{kV}$ for all experiments.

\section{Results and Discussion}

We previously investigated the parameters influencing the SERS spectra of bacteria when a simple mixing of bacterial cells with colloidal nanoparticles was employed as a sample preparation method $[11,12]$. One of the principle requirements in a SERS experiment is to bring the noble metal nanoparticles or nanostructures close contact with molecules and molecular structures. This necessity is set by the mechanism of Raman signal enhancement due to the fact that the major contribution to the enhancement mechanism comes from the surface plasmons (SPs). Therefore, molecular structures such as bacterial cells must be at close contact with as many as noble metal nanoparticles when a noble metal colloidal suspension is used for the SERS experiment. In our earlier study, we demonstrated that increasing the colloidal suspension concentration four times $(4 \mathrm{x})$ improved not only the reproducibility but also the quality of SERS spectra due to the increased density of AgNPs in the sample compared to the previous reports [11]. Figure 2(a) shows the SEM image of E. coli sample prepared with $4 \mathrm{x}$ colloidal suspension and Figure 2(b) shows the SERS spectra acquired from ten different spots on the sample. As seen, the AgNPs are heterogeneously distributed among the bacterial cells, which results with variations on the spectra as the laser beam is moved on the sample. The microwells are expected to provide a three-dimensional (3D) environment generating many contact points for the bacterial cells to sense the SPs, which could improve the spot-to-spot variations and obtain more reproducible SERS spectra. Figure 3 shows a typical microwell-constructed surface containing $S$. cohnii cells. Considering size of $S$. cohnii $(\sim 0.8 \mu \mathrm{m})$ obtained from the SEM images, a size relationship between bacterial cells

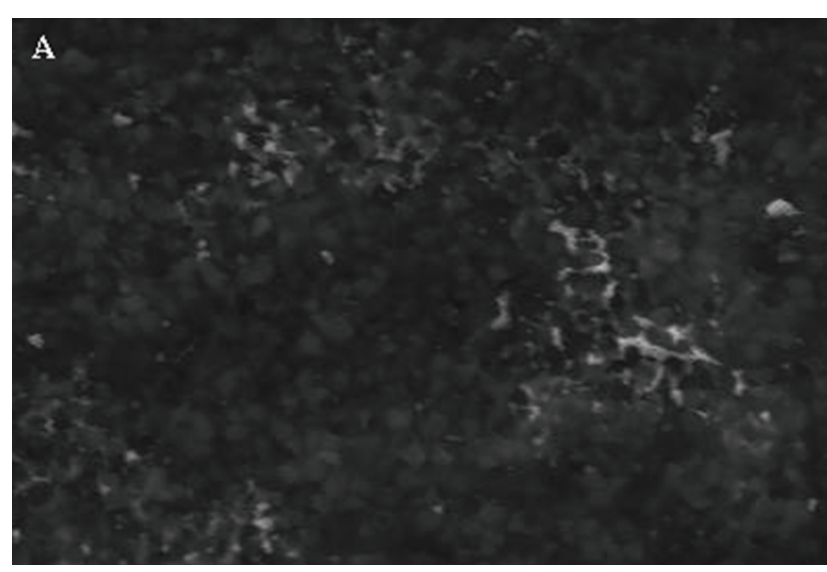

(a)

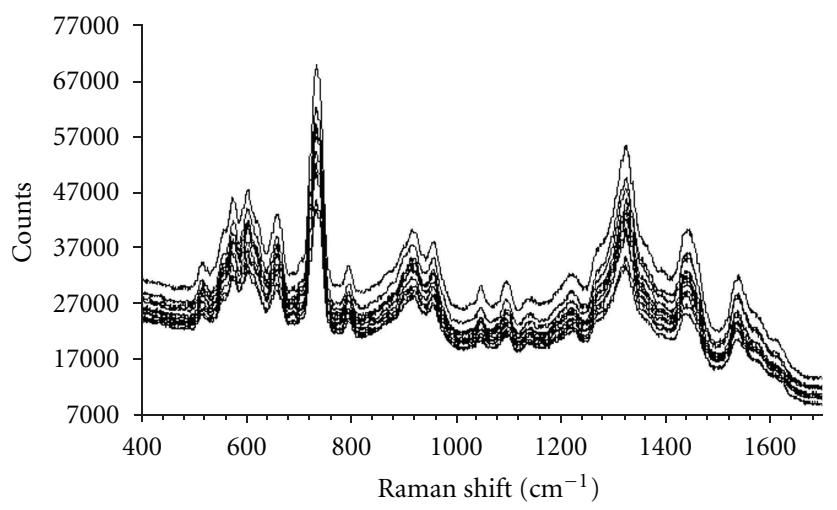

(b)

FIGURE 2: SEM image of an E. coli sample prepared with 4x colloidal suspension (a) and the ten SERS spectra generated from this sample from different locations (b).

and microwell size $(1.2 \mu \mathrm{m})$ can be correlated. However, the aggregation tendency of the bacterial cells influence the uniform distribution of bacterial cells in the microwells and prevents filling all microwells with bacterial cells. Therefore, a dilution step is necessary to have the bacterial cells distribute appropriately in the microwells as explained in the experimental section.

Figure 4(a) shows the SEM images of microwells containing E. coli cells. A size relationship between E. coli and microwells can also be defined based on the possible orientation of the E. coli cells in the microwells. The average size of $E$. coli cells is measured from their SEM images (see Figure $4(\mathrm{~b})$ ) as $1.8 \times 0.9 \mu \mathrm{m}$, length and diameter, respectively. Either 1 or $2 \mathrm{E}$. coli cells in each microwell can fit depending on the orientation of E. coli cells on the substrate surface. Although it was not possible to clearly visualize the $E$. coli cells in the microwells on the SEM images, the presence of bacterial cells on the substrate was confirmed with AFM as seen on Figure 4(b). In addition, obtaining SERS spectra from the surfaces verifies the presence of the bacterial cells in the microwells. The difficulty to visualize the E. coli cell on the samples prepared with simple mixing was also observed (see Figure 2(a)). 


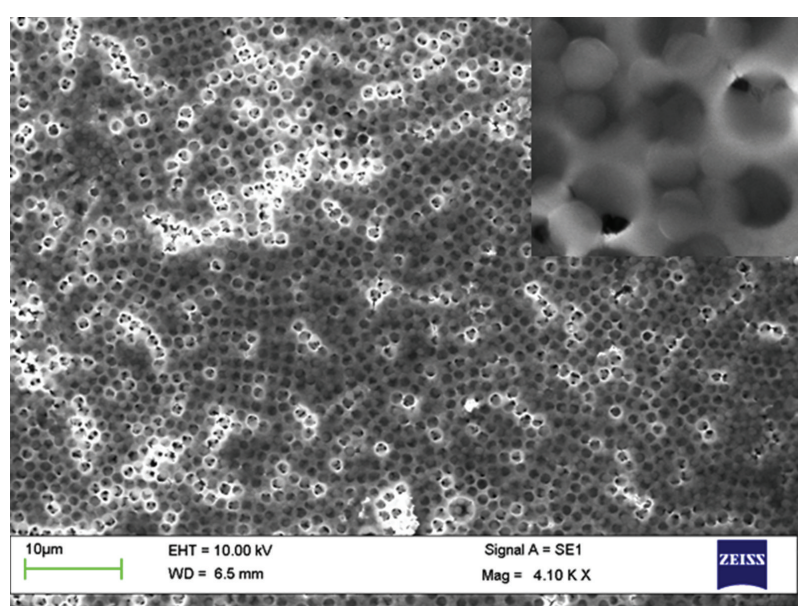

FIgURE 3: SEM image of S. cohnii in the microwells constructed from AgNPs. Inset image shows a closer caption of the bacterial cells.

It is important to select proper laser wavelength for good quality of SERS spectra from bacteria [12]. Efrima and Zeiri also demonstrated the influence of the laser wavelength and power on the SERS of bacteria [23]. The shift of SP excitation to longer wavelengths as the noble metal nanoparticles form aggregates is a well known phenomenon. Therefore, a longer wavelength laser is more suitable to excite the SPs of aggregated AgNPs. It was indeed a laser wavelength at $514 \mathrm{~nm}$ did not perform as good as a laser wavelength at $830 \mathrm{~nm}$ in this study. Besides, this wavelength is more suitable for study of biological samples since the damage to the sample in NIR region is limited.

Due to the noteworthy differences in both approaches, simple mixing and in microwells, it is important to understand the spectral features on the SERS spectrum generated from each method. Figure 5 shows the comparison of the SERS spectra of E. coli taken from a sample prepared with simple mixing of $4 \mathrm{x}$ AgNPs and in the microwells.

The comparative inspection of both spectra reveals many spectral differences. However, the major difference is observed in the region from 500 to $700 \mathrm{~cm}^{-1}$. While the five peaks at 526,564, 582,610, and $664 \mathrm{~cm}^{-1}$ appear in this region on the spectra acquired from the sample prepared with simple mixing, only three peaks at 520, 571 , and $621 \mathrm{~cm}^{-1}$ are observed in microwells. The peaks around $500 \mathrm{~cm}^{-1}$ on the SERS of proteins and peptides were attributed to $S-S$ stretch [24] and the peak around 520 and $526 \mathrm{~cm}^{-1}$ on both spectra can be assigned to S-S stretch [25] Due to the fact that thiol moieties interact strongly with AgNPs, the band shifts may be observed on the SERS spectra upon interaction of such groups on the bacterial cell wall with the AgNPs when considering the free AgNPs present upon mixing with bacterial cells. The peaks on simple mixing spectra at 564, 582, 610 , and $664 \mathrm{~cm}^{-1}$ and 660 and $630 \mathrm{~cm}^{-1}$ could be attributed to carbohydrates [26] and $\mathrm{COO}^{-}$[27], respectively. Note that we earlier determined that the source of spectral features was originating from the bacteria [28]. However, as seen above, even with the use of same laser

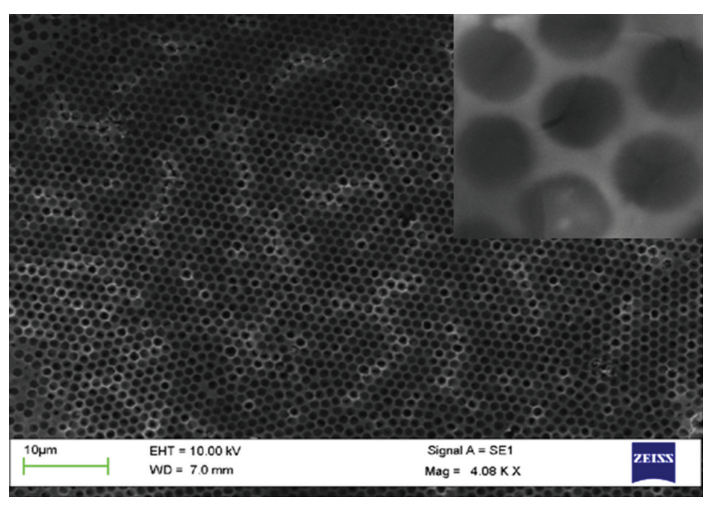

(a)

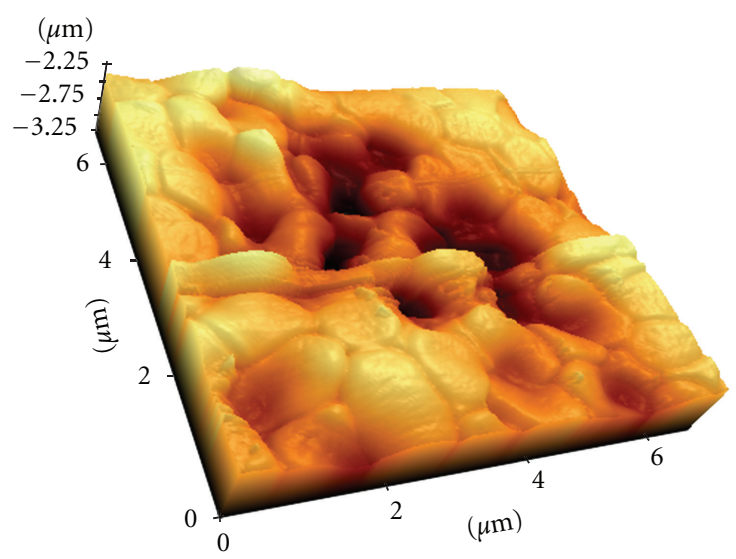

(b)

FIGURE 4: SEM (a) and AFM (b) image of E. coli cells in microwells. Inset image shows a closer caption of the bacterial cells.

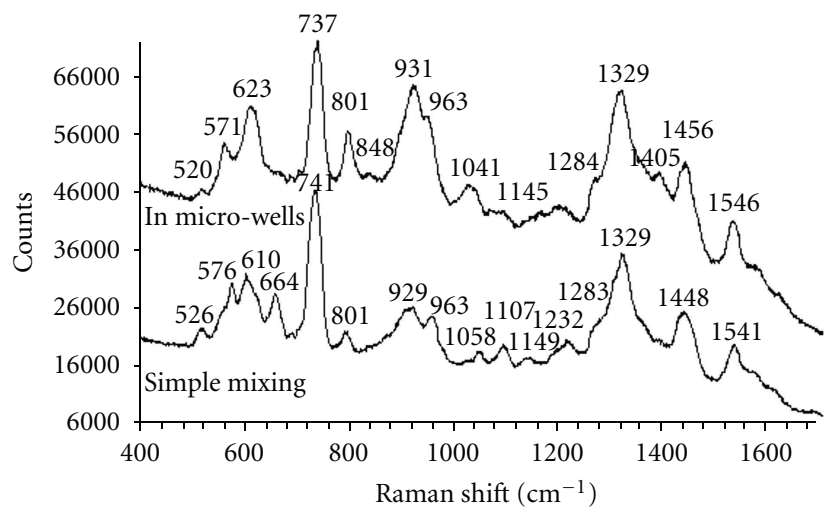

FIgure 5: Comparison of SERS spectra of E. coli obtained in microwells and with simple mixing.

and type of the NPs, variations on the spectral features are observed.

Figure 6 shows the comparison of SERS spectra of $S$. cohnii obtained from a sample prepared simple mixing of $4 \mathrm{x}$ AgNP colloidal suspension and in the microwells. As seen, the SERS spectra obtained from the samples prepared with simple mixing and adding into the microwells are strikingly similar. This similarity can be explained with the 


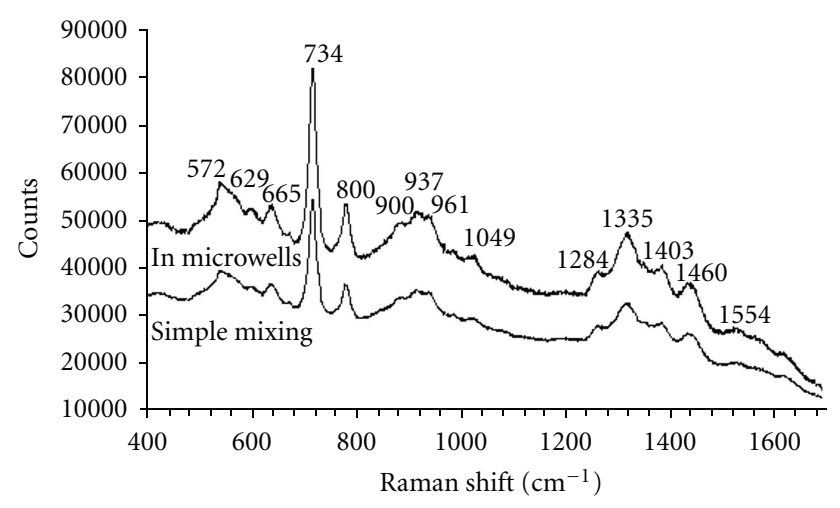

Figure 6: Comparison of SERS spectra of $S$. cohnii obtained in microwells and with simple mixing.

bacterial cell wall structures as well. S. cohnii is a Grampositive bacteria and its cell wall biochemistry is completely different compared to Gram-negative bacteria. The outer wall structure is composed of a thick peptidoglycan structure that is rich in $\mathrm{N}$-acetyl D-glucoseamine (NAG). In addition, this strong structure peptidoglycan structure has a more uniform structure compared to Gram-negative bacterial outer cell wall. The similarity of the spectra may refer to the uniform wall structure of this bacterium. The peaks appearing on the SERS spectra can be assigned to similar bond vibrations as they are in SERS spectra of E. coli.

The biochemical structures giving rise to the peaks on the SERS spectra of bacteria are not clearly known yet. There are a number of parameters influencing the spectra of bacteria imposed by the nature of the microbiological materials and the technique. There are several reports from sample preparation to experimental conditions such as laser wavelength, nanoparticle, and substrate type addressing the source of the variations on the SERS spectra of microorganisms $[12,23,28-30]$. From these studies, it is clear that a well-defined protocol is necessary for reproducible and interpretable results.

In order to demonstrate the spot-to-spot reproducibility, several spectra were acquired from different location on the same sample. Figures 7(a) and 7(b) shows reproducibility of SERS spectra of E. coli and S. cohnii, respectively. The percent coefficient of variation $(\mathrm{CV})$, which is defined as standard deviation $(s) /$ mean $(\chi) \times 100$, can be used to quantify the variation in SERS spectra of the bacteria obtained from the samples. The CV using peak height, absolute intensity, and peak area can be calculated at every frequency for a number of spectra. Either a \%CV value at a certain frequency or an average from the calculated \%CV at every frequency can be calculated for the quantification of variation. In this study, we used the peak height, absolute intensity, and peak area at around $737 \mathrm{~cm}^{-1}$ to express the reproducibility of the spectra through the \%CV values. The \%CV for the E. coli in the microwells using the peak height, absolute intensity, and peak area was calculated as 12,10 , and 10 , respectively. However, the \%CV with simple mixing method was 17,18 , and 19 , respectively. The \%CV for the E. coli sample prepared

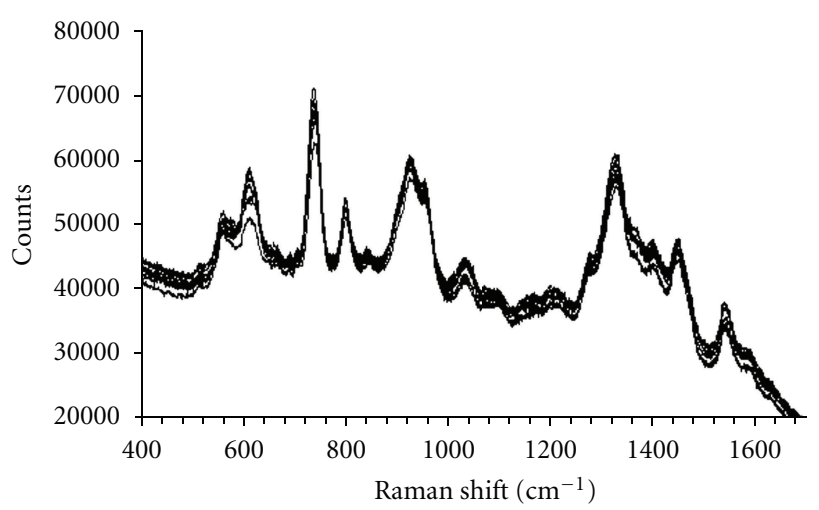

(a)

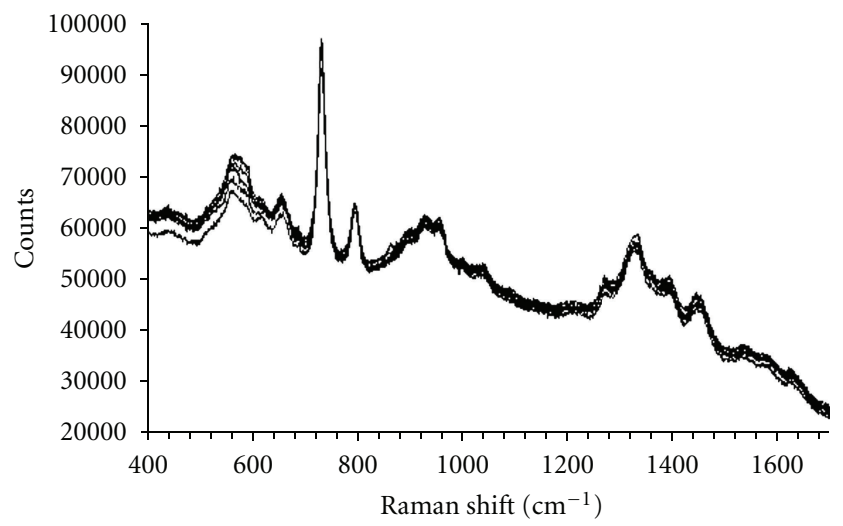

(b)

FIGURE 7: Reproducibility of SERS spectra of E. coli (a) and S.cohnii (b). SERS spectra acquired from different locations on AgNP microwell structure.

with "convective-assembly" process using the peak height, absolute intensity and peak area was calculated as 9, 8 , and 8 , respectively. The \%CV for $S$. cohnii in microwells was 2,1 , and 5 , respectively, but it was 12,11 , and 15 , respectively, for simple mixing. The \%CV for the S. cohnii sample prepared with convective assembly process using the peak height, absolute intensity, and peak area was calculated as 6, 6, and 7 , respectively. When the two sample preparation methods are compared, the reproducibility of SERS spectra for E. coli is quite similar. However, in this method the reproducibility of the SERS spectra for $S$. cohnii is higher than the sample prepared with convective assembly method. With the simple mixing, the \%CVs of both bacteria are very similar. However, the reproducibility of the spectra of the $S$. cohnii acquired in the microwells was more reproducible than the E. coli due to the size and shape related homogeneity of the cells in the microwells. The shape of the prepared wells is spherical, which is similar in size and shape of S. cohnii and they can enter into the wells easily and homogeneously. However, E. coli is rod-shaped and its entrance into the wells is hindered. Therefore, the improvement of the reproducibility is lower for the E. coli. This can be easily concluded from Figures 3 and 4 . 
The improvement in percent CV in microwells is higher than $40 \%$ for E. coli and $70 \%$ for S. cohnii compared to the simple mixing with $1 \mathrm{x}$ colloidal AgNP suspension. The improvement in CV of peak height, area, and absolute intensity was in the range $60-63 \%$ for E. coli and $58-61 \%$ for $S$. cohnii from the sample prepared with $1 x$ colloidal suspension to the sample prepared with "convective-assembly." When the results of this study are compared to our previous study using "convective-assembly" [13], the improvement in reproducibility is rather similar.

\section{Conclusion}

In this study, the utility of microwell structures constructed from AgNPs for whole bacterial characterization using SERS and an analysis of the obtained bacterial SERS spectra for possible discrimination or identification is demonstrated. Since the size of majority of clinically important bacteria is already known, the SERS substrates with different size of microwells can be preprepared. As the AgNPs form organized aggregates in the well structure, the SP excitation wavelength shifts to longer wavelength. Therefore, a longer wavelength laser light is a proper choice for better quality of bacterial SERS in the prepared structures. The placement of bacterial cells in microwells significantly improves the reproducibility of the SERS spectra of bacteria used in this study. Thus, the SERS spectra can be used for fast bacterial identification.

\section{Acknowledgments}

The support of the Scientific and Technological Research Council of Turkey (TUBITAK) and Yeditepe University is gratefully acknowledged.

\section{References}

[1] R. E. Holt and T. M. Cotton, "Surface-enhanced resonance Raman and electrochemical investigation of Glucose Oxidase catalysis at a silver electrode," Journal of the American Chemical Society, vol. 111, no. 8, pp. 2815-2821, 1989.

[2] S. Efrima and B. V. Bronk, "Silver colloids impregnating or coating bacteria," Journal of Physical Chemistry B, vol. 102, no. 31, pp. 5947-5950, 1998.

[3] L. Zeiri, B. V. Bronk, Y. Shabtai, J. Eichler, and S. Efrima, "Surface-enhanced Raman spectroscopy as a tool for probing specific biochemical components in bacteria," Applied Spectroscopy, vol. 58, no. 1, pp. 33-40, 2004.

[4] L. Zeiri and S. Efrima, "Surface-enhanced Raman spectroscopy of bacteria: the effect of excitation wavelength and chemical modification of the colloidal milieu," Journal of Raman Spectroscopy, vol. 36, no. 6-7, pp. 667-675, 2005.

[5] A. Sengupta, M. L. Laucks, and E. James Davis, "Surfaceenhanced Raman spectroscopy of bacteria and pollen," Applied Spectroscopy, vol. 59, no. 8, pp. 1016-1023, 2005.

[6] A. Sengupta, M. Mujacic, and E. J. Davis, "Detection of bacteria by surface-enhanced Raman spectroscopy," Analytical and Bioanalytical Chemistry, vol. 386, no. 5, pp. 1379-1386, 2006.

[7] M. L. Laucks, A. Sengupta, K. Junge, E. J. Davis, and B. D. Swanson, "Comparison of psychro-active arctic marine bacteria and common mesophillic bacteria using surfaceenhanced raman spectroscopy," Applied Spectroscopy, vol. 59, no. 10, pp. 1222-1228, 2005.

[8] R. M. Jarvis and R. Goodacre, "Discrimination of bacteria using surface-enhanced Raman spectroscopy," Analytical Chemistry, vol. 76, no. 1, pp. 40-47, 2004.

[9] R. M. Jarvis, A. Brooker, and R. Goodacre, "Surface-enhanced Raman spectroscopy for bacterial discrimination utilizing a scanning electron microscope with a Raman spectroscopy interface," Analytical Chemistry, vol. 76, no. 17, pp. 5198-5202, 2004.

[10] W. R. Premasiri, D. T. Moir, M. S. Klempner, N. Krieger, G. Jones, and L. D. Ziegler, "Characterization of the surface enhanced Raman scattering (SERS) of bacteria," Journal of Physical Chemistry B, vol. 109, no. 1, pp. 312-320, 2005.

[11] M. Kahraman, M. M. Yazici, F. Şahin, Ö. F. Bayrak, and M. Çulha, "Reproducible surface-enhanced Raman scattering spectra of bacteria on aggregated silver nanoparticles," Applied Spectroscopy, vol. 61, no. 5, pp. 479-485, 2007.

[12] M. Kahraman, M. M. Yazici, F. Şahin, and M. Çulha, "Experimental parameters influencing surface-enhanced Raman scattering of bacteria," Journal of Biomedical Optics, vol. 12, no. 5, Article ID 054015, 2007.

[13] M. Kahraman, M. M. Yazici, F. Şahin, and M. Çulha, "Convective assembly of bacteria for surface-enhanced Raman scattering," Langmuir, vol. 24, no. 3, pp. 894-901, 2008.

[14] N. D. Denkov, O. D. Velev, P. A. Kralchevsky, I. B. Ivanov, H. Yoshimura, and K. Nagayama, "Mechanism of formation of two-dimensional crystals from latex particles on substrates," Langmuir, vol. 8, no. 12, pp. 3183-3190, 1992.

[15] N. D. Denkov, O. D. Velev, P. A. Kralchevsky, I. B. Ivanov, H. Yoshimura, and K. Nagayama, "Two-dimensional crystallization,” Nature, vol. 361, no. 6407, p. 26, 1993.

[16] P. M. Tessier, S. D. Christesen, K. K. Ong et al., "Online spectroscopic characterization of sodium cyanide with nanostructured gold surface-enhanced Raman spectroscopy substrates," Applied Spectroscopy, vol. 56, no. 12, pp. 15241530, 2002.

[17] M. Brust, D. Bethell, C. J. Kiely, and D. J. Schiffrin, "Selfassembled gold nanoparticle thin films with nonmetallic optical and electronic properties," Langmuir, vol. 14, no. 19, pp. 5425-5429, 1998.

[18] T. Ung, L. M. Liz-Marzán, and P. Mulvaney, "Gold nanoparticle thin films," Colloids and Surfaces A, vol. 202, no. 2-3, pp. 119-126, 2002.

[19] P. M. Tessier, O. D. Velev, A. T. Kalambur, A. M. Lenhoff, J. F. Rabolt, and E. W. Kaler, "Structured metallic films for optical and spectroscopic applications via colloidal crystal templating," Advanced Materials, vol. 13, no. 6, pp. 396-400, 2001.

[20] P. M. Tessier, O. D. Velev, A. T. Kalambur, J. F. Rabolt, A. M. Lenhoff, and E. W. Kaler, "Assembly of gold nanostructured films templated by colloidal crystals and use in surfaceenhanced Raman spectroscopy," Journal of the American Chemical Society, vol. 122, no. 39, pp. 9554-9555, 2000.

[21] P. C. Lee and D. Meisel, "Adsorption and surface-enhanced Raman of dyes on silver and gold sols," The Journal of Physical Chemistry, vol. 88, p. 3391, 1982.

[22] B. G. Prevo and O. D. Velev, "Controlled, rapid deposition of structured coatings from micro- and nanoparticle suspensions," Langmuir, vol. 20, no. 6, pp. 2099-2107, 2004.

[23] S. Efrima and L. Zeiri, "Understanding SERS of bacteria," Journal of Raman Spectroscopy, vol. 40, no. 3, pp. 277-288, 2009. 
[24] S. Steward and P. M. Fredericks, "Surface-enhanced Raman spectroscopy of peptides and proteins adsorbed on an electrochemically prepared silver surface," Spectrochimica Acta Part A, vol. 55, p. 1615, 1999.

[25] K. Maquelin, C. Kirschner, L. P. Choo-Smith et al., "Identification of medically relevant microorganisms by vibrational spectroscopy," Journal of Microbiological Methods, vol. 51, no. 3, pp. 255-271, 2002.

[26] R. Keir, D. Sadler, and W. E. Smith, "Preparation of stable, reproducible silver colloids for use as surface-enhanced resonance Raman scattering substrates," Applied Spectroscopy, vol. 56, no. 5, pp. 551-559, 2002.

[27] K. C. Schuster, I. Reese, E. Urlaub, J. R. Gapes, and B. Lendl, "Multidimensional information on the chemical composition of single bacterial cells by confocal Raman microspectroscopy," Analytical Chemistry, vol. 72, no. 22, pp. 5529-5534, 2000.

[28] M. Kahraman, K. Keseroğlu, and M. Çulha, "On sample preparation for surface-enhanced Raman scattering (SERS) of bacteria and the source of spectral features of the spectra," Applied Spectroscopy, vol. 65, no. 5, pp. 500-506, 2011.

[29] W. R. Premasiri, Y. Gebregziabher, and L. D. Ziegler, "On the difference between surface-enhanced Raman scattering (SERS) spectra of cell growth media and whole bacterial cells," Applied Spectroscopy, vol. 65, no. 5, pp. 493-499, 2011.

[30] T. Smith-Palmer, C. Douglas, and P. Fredericks, "Rationalizing the SER spectra of bacteria," Vibrational Spectroscopy, vol. 53, no. 1 , pp. 103-106, 2010. 

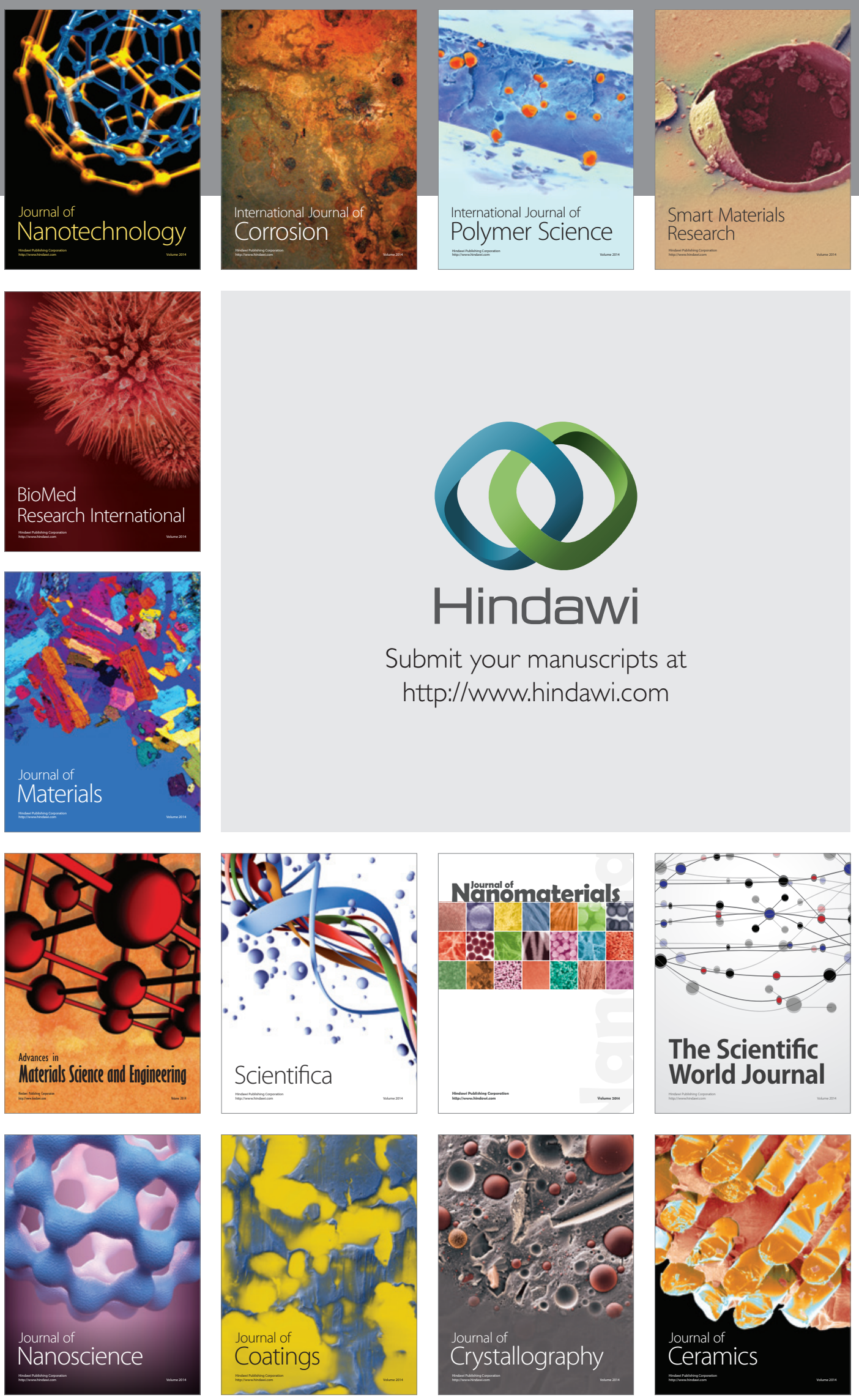

The Scientific World Journal

Submit your manuscripts at

http://www.hindawi.com

\section{World Journal}

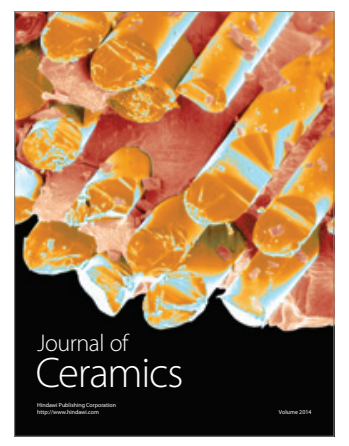

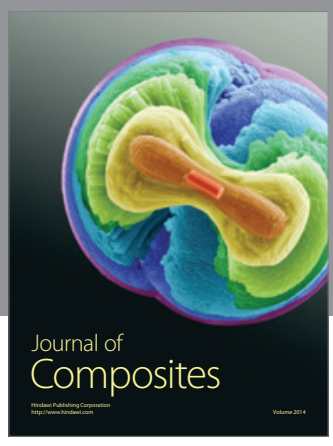
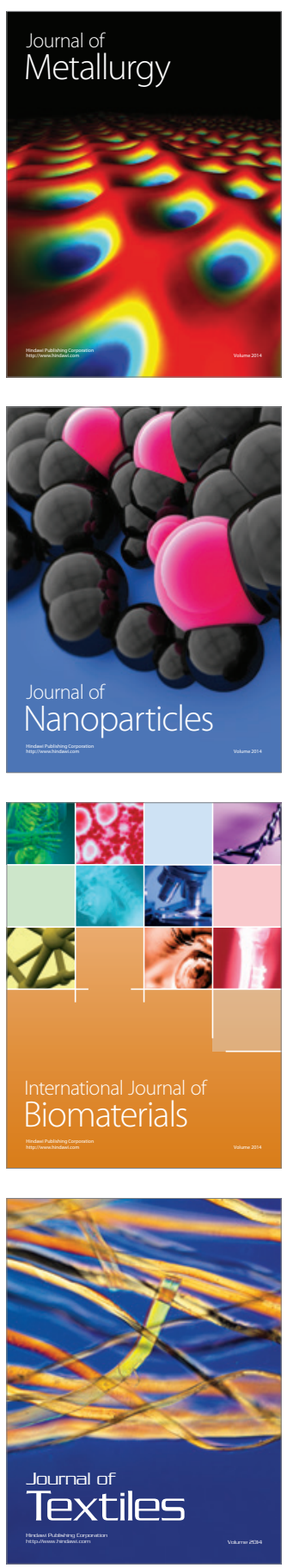